\title{
Literatur
}

1. Davis, B. J. und L. Ornstern, A new high resolution electrophoresis method. Delivered at the Society for the study of blood, New York Academy of Medicine, on the 24th March 1959. 2. RAYMOND, S. und L. S. Weintraub, Science (Washington) 130 , 711 (1959). - 3. Rerspeld, R. A., U. J. Lewis und D. E. WirLIAMS, Nature (London) 195, 281 (1962). - 4. Davis, B. J., Ann. N. Y. Acad. Sci. 121, 404 (1964). - 5. Smithies, O., Adv. Protein Chem. 14, 65 (1959). - 6. OTr, H., Med. Welt, 51, 2697 (1960). 7. Tasweld, H. F. und D. M. Jeffers, Amer. J. Clin. Path. 40, 349 (1963). - 8. Vgl. Sснмidt, E., F. W. Schmidt, H. D. HorN, und U. GerLACH in "Methoden der enzymatischen Analyse“
S. $651-712$, Hrsg. H. U. Bergmeyer, Verlag Chemie GmbH Weinheim/Bergstr. (1962). - 9. Vgl. Hodson, A. W., A. L. Laureen Raine, Clin. chim. Acta (Amsterdam) 7, 255 (1962). 10. Vgl. Estborn, B., diese Z. 2, 53 (1964). - 11. Vgl. Luzzio, A. J., Proc. Soc. Exper. Biol. Med. N. Y. 116, 769 (1964). - 12. Maurer, H.R., Disk-Elektrophorese, W. de Gruyter \& Co. Berlin (1968). - 13. Rosenber G, I. N., J. Clin. Invest. 38, 630 (1959). 14. Kaplan, A. und A. Narahara, J. Laborat. Clin. Med. S. Louis 41, 819 (1953). - 15. Kärcher, K. H. und G. Schulz, Strahlentherapie 131, 395 (1966).

Prof. Dr. K. H. Kärcher 69 Heidelberg, Voßstr. 3

\section{Verfolgung der Zusammensetzung der veresterten Fettsäuren im Kaninchenserum während einer experimentellen alimentären Lipämie}

\author{
Von W. Priz') \\ Aus dem Pbysiologisch-Chemischen und Analytischen Labor (Leiter: Dr. W. Pilz) der Ärztuichen Abteilung \\ (Leiter: Dr. H. Hörlein) der Farbenfabriken Bayer AG, Werk Leverkusen
}

(Eingegangen am 28. Oktober 1967)

Im Anschluß an Untersuchungen über das Arylesterasesystem des Kaninchens wurde die Verteilung der veresterten Fettsäuren bei nüchternen Tieren, bei Tieren mit einer experimentellen alimentären Lipämie und bei solchen, denen Blut 24 Stdn. nach der Lipämie entnommen wurde, untersucht. Mit der präparativen Stärkebreielektrophorese lassen sich veresterte Fettsäuren enthaltende Fraktionen im Bereich des Präalbumins und Albumins, $\operatorname{der} \alpha$-, $\beta$ - und $\gamma$-Globuline isolieren. Im nüchternen Zustand haben alle 4 Fraktionen einen erheblichen Anteil an niederkettigen Fettsäuren, darunter besonders das Präalbumin. Alle 4 Fraktionen sind in der Lage, ihre als Ester gebundenen kurzkettigen Fettsäuren gegen Ester langkettiger Fettsäuren auszutauschen. Im Zustand einer alimentären Lipämie sinkt der Anteil der veresterten niederkettigen Fettsäuren auf ein Minimum ab, um dann später wieder seinen alten Stand annähernd zu erreichen. Es kommen nur jene niedrigen Fettsäuren in veresterter Form vor, die als Phenylester und Tyrosinester Substrate für die Arylesterasen im Kaninchenserum sind. Die Befunde stehen im Einklang mit unserer Theorie, daß der Transport der langkettigen Fettsäuren im Serum über eine von den Arylesterasen katalysierte Umesterung (kurzkettige aromatische Ester + langkettige Fettsäuren = langkettige aromatische Ester + kurzkettige Fettsäuren) erfolgt.

In connection with studies on the aryl esterase system of the rabbit, the distribution of esterified fatty acids was investigated in resting animals and in animals with an experimental alimentary lipaemia, both during and $24 \mathrm{hr}$. after the lipaemia. By preparative starch gel electrophoresis, fractions containing esterified fatty acids were isolated from the areas containing prealbumin and albumin, $\alpha$-, $\beta$ - and $\gamma$-globulins. In the resting state, all 4 fractions contain a high proportion of short chain fatty acids, especially the prealbumin fraction. All 4 fractions will exchange their ester-bound short chain fatty acids with the esters of long chain fatty acids. In alimentary lipaemia, the proportion of esterified short chain fatty acids decreases to a minimum, but the level increases again later and approaches the previous value. The only short chain fatty acids that are found esterified are those which, as phenyl- and tyrosine-esters, act as substrates for the aryl esterases in rabbit serum. These findings agree with our theory that the transport of long chain fatty acids in serum is achieved by a transesterification catalysed by one of the aryl esterases (short chain aromatic ester + long chain fatty acid = long chain aromatic ester + short chain fatty acid).

Bei unseren Studien über die Arylesterasen²) des menschlichen Serums (1) konnten wir feststellen, daß die Arylesterase I durch langkettige Fettsäuren scheinbar gehemmt wird. Wie wir später fanden (2), war diese scheinbare Hemmung durch die Umesterung bedingt. Da bei unseren Methoden zur Bestimmung der Arylesterase (1, 3) das Spaltprodukt $\beta$-Naphthol photometrisch bestimmt wird, war der primäre Eindruck einer Hemmung zu erklären, da kein freies $\beta$-Naphthol bei der Reaktion entsteht. Später fanden wir, $\mathrm{da} \mathrm{B}$ im menschlichen Nabelschnurserum ebenfalls

\footnotetext{
1) Auszugsweise vorgetragen auf der Wintertagung der Deutschen Gesellschaft für Biologische Chemie am 9. 1. 1968 in München. 2) Verwendete Trivialnamen: Arylesterase = Aryl-Ester Hydrolase (EC 3.1.1.2); Clearing Enzyme (12) = endogene Lipoproteidlipase $=$ Glycerin-Ester Hydrolase (EC 3.1.1.3).
}

Arylesterasen enthalten sind, die zum Teil die Fähigkeit zur Umesterung besitzen (4). Schließlich konnten wir nach der Auftrennung eines Vollhomogenates aus Menschen-Leber ein Enzym isolieren, das in der entgegengesetzten Richtung umestert (5). Damit war erwiesen, daß es sich bei den Arylesterasen um Enzyme des Fettstoffwechsels, speziell des Fettsäuretransportes handelt. Das Arylesterasesystem läßt sich wie folgt vereinfacht darstellen (Mensch):

Serum: Tyrosinester niederkettiger Fettsäuren + freie langkettige Fettsäuren $=$ Tyrosinester langkettiger Fettsäuren + freie kurzkettige Fettsäuren.

Leber: Tyrosinester langkettiger Fettsäuren + kurzkettige Fettsäuren = Tyrosinester kurzkettiger Fettșäuren + freie langkettige Fettsäuren. 


\section{Bemerkung :}

Bei diesem Schema handelt es sich nicht um freies Tyrosin, sondern um Tyrosin, das Bestandteil intakter Proteine ist.

Bei experimentellen Arbeiten werden als Substrate für die Bestimmung der Arylesterasen im Serum Phenylacetat und $\beta$-Naphthylpropionat verwendet. Die beiden Ester stellen das Optimum der Kettenlänge der Fettsäuren für das entsprechende Phenol dar (Mensch). Beide sind synthetische Substrate. Wie wir seit längerer Zeit wissen, und in Kürze ausführlich darlegen werden, hat sich von 128 verschiedenen Phenolen, die mit den Fettsäuren $C_{2}$ bis $C_{18}$ verestert waren, Tyrosinacetat als jene Verbindung herausgestellt, die von der Arylesterase I des menschlichen Serums bei weitem am schnellsten hydrolysiert wird.

Tyrosinacetat war zwar immer noch ein synthetisches Substrat; es lieferte jedoch die Anregung, Tyrosin enthaltende Serumfraktionen des Menschen, die mit Hilfe der präparativen Stärkebreielektrophorese rein gewonnen wurden, als Substrate zu verwenden, sofern sie veresterte Essigsäure enthielten. Abbildung 1 stellt

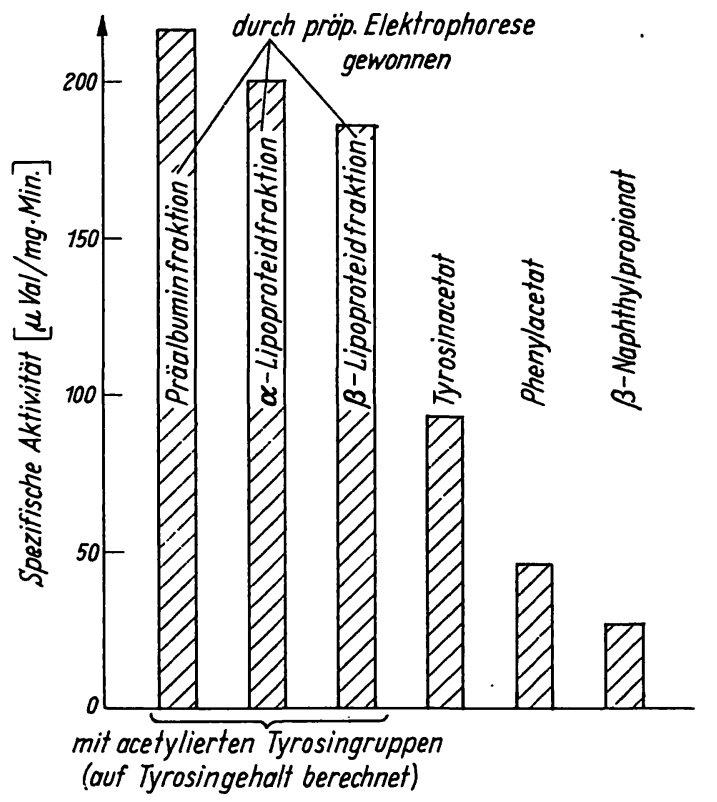

Abb. 1

Aktivitätsvergleich für synthetische und physiologische Substrate für die isolierte Arylesterase I (Mensch). Substratkonzentration $1,33 \mathrm{mMol} / l ; 1 \mathrm{ml}$ Enzymlösung; Inkubationsdauer 30 Min. $\mathrm{pH} 8,2,37^{\circ}$.

als Beispiel das Ergebnis eine1 derartigen Unterșuchung dar. In der Abbildung sind jene Proteinfraktionen ausgewählt, deren Gehalt an veresterter Essigsäure am höchsten war. Sie enthalten $3 \%$ bis $5 \%$ Tyrosin, wovon - sofern von Serum nüchterner Versuchspersonen ausgegangen wird $-80 \% \pm 5 \%$ mit Essigsäure verestert sind. Die Arylesterase I des menschlichen Serums hydrolysiert aber nicht nur die Acetylgruppen, sondern katalysiert auch die oben beschriebene Umesterung im gleichen Sinne wie sie für die synthetischen Substrate beschrieben wurde $(2,4,5)$ (vgl. obiges Schema). Zum Vergleich sind auch die Hydro- lyseraten für die üblicherweise im Labor verwendeten Substrate Tyrosinacetat, Phenylacetat und $\beta$-Naphthylpropionat eingezeichnet.

Wir haben vor kurzem (6) die Arylesterasen des $\mathrm{Ka}$ ninchenserums untersucht und konnten dabei 12 verschiedene Enzyme isolieren. Wegen des Umfanges der dabei erhaltenen Ergebnisse wird das Gebiet gesondert dargestellt. Wir teilen für das Verständnis der vorliegenden Arbeit jedoch im voraus mit, daB die Arylesterasen des Kaninchenserums Phenylester, deren Fettsäurekomponenten die Kettenlängen $\mathrm{C}_{2}, \mathrm{C}_{3}, \mathrm{C}_{5}$ und $\mathrm{C}_{6}$ haben, in Gegenwart freier langkettiger Fettsäuren zu Phenylestern langkettiger Fettsäuren umestern. Dasselbe gilt auch für eine Reihe von aus Nüchternserum rein gewonnenen Proteinfraktionen, insbesondere die Fraktionen 20, 32, 60, 73 und 116 (vgl. weiter unten).

Wie bereits früher im Falle des Nabelschnurserums (4) haben wir auch im Kaninchenserum nach dem Vorhandensein von Estern jener Fettsäuren gesucht, die als Substrate in Frage kommen und festgestellt, daß Ester dieser Säuren in kleiner Menge im Kaninchenserum anwesend sind. Eine quantitative Untersuchung über das Umesterungsverhalten einiger diese Ester enthaltenden isolierten Proteinfraktionen wird im Kapitel „Ergebnisse“ beschrieben.

Wir haben weiterhin Serum von nüchternen Kaninchen, Serum von Kaninchen, die eine experimentelle alimentäre Lipämie hatten, sowie Serum von Tieren nach Abklingen der Lipämie gewonnen, mit Hilfe der Stärkebreielektrophorese präparativ aufgetrennt und in allen Fraktionen die veresterten Fettsäuren bestimmt. Alle jene Fraktionen, die veresterte Fettsäuren enthielten, wurden zur Identifizierung der Kettenlänge als Eisen(III)-Hydroxamate chromatographiert. Auf diese Weise konnte die Fettsäurezusammensetzung der einzelnen Serumfraktionen und schließlich der Transportmechanismus für freie langkettige Fettsäuren während des Ablaufes einer Lipämie verfolgt werden.

\section{Material und Methoden}

In dem Versuch wurden weibliche Kaninchen (Neuseeländer, silbergrau) mit einem Gewicht von 4000 bis $4500 \mathrm{~g}$ verwendet. Serum wurde in allen Fällen durch Herzpunktion, 2stdg. Stehenlassen bei Zimmertemperatur und Zentrifugieren gewonnen. Die künstliche Lipämie wurde durch i.v.-Injektion von je $1,5 \mathrm{~m} l$ Lipofundiñ ${ }^{3}$ ) (10proz.) in 4stdg. Abständen über einen Zeitraum von $24 \mathrm{Stdn}$. in die Vena auricularis erzeugt.

$\mathrm{Zu}$ Beginn des Versuches wurden 30 Kaninchen in frisch zubereitete Einzelställe gebracht; sie mußten 24 Stdn. fasten (wobei sie Wasser ad libitum bekamen). Nach Ablauf der 24 Stdn. wurde bei 10 Tieren eine Herzpunktion durchgeführt und die gewonnenen Seren vereinigt (Untersuchungsgut (a)). Die restlichen $20 \mathrm{Ka}-$ ninchen wurden während der folgenden $24 \mathrm{Stdn}$. wie oben beschrieben mit Lipofundin ernährt; $10 \mathrm{Min}$. nach der letzten Fettgabe wurden 10 Tiere herzpunktiert und wie oben das Serum gewonnen (lipämisches Serum (b)). Die testlichen 10 Tiere wurden im AnschluB an die 24stdg. Fettbelastung weitere $24 \mathrm{Stdn}$. ohne Nahrung gehalten, wobei sie Wasser ad libitum erhielten. Nach

3) Hersteller: B. Braun, Melsungen. 
Ablauf dieser Zeit wurden auch bei diesen Tieren Herzpunktionen vorgenommen und das Serum wie oben beschrieben gesammelt. Untersuchungsgut war somit Nüchternserum (a), Serum das 10 Min. nach Fettbelastung gewonnen wurde (lipämisches Serum (b)) und Serum von Tieren, die nach der Fettbeladung 24 Stdn. gefastet hatten (c).

Stärkebreielektrophoresen wurden nach dem früher beschriebenen Prinzip (7) durchgeführt, jedoch entsprechend der Problemstellung folgende Änderung vorgenommen: Als Puffer diente 0,05M.Tris-Essigsäure (8) $\mathrm{pH}$ 6,2. Dic Stärkeblöcke hatten eine Dimension von $10 \times 100 \times 2 \mathrm{~cm}$ und wurden vor dem Auftragen des Untersuchungsgutes durch Höherheizen der Kühlvorrichtung so weit getrocknet, $\mathrm{da} B$ eben noch keine Sprünge im Block entstanden. Vor dem Auftragen des Untersuchungsmaterials wurde der Block auf $+1^{\circ}$ abgekühlt. Die Auflagefläche der Elektroden (10fach gelegtes Papier, Binzer Nr. 201, luftdicht in Perlonfolie eingeklebt) war auf beiden Seiten etwa $2 \mathrm{~cm}$.

Bei Verwendung von $0,1 \mathrm{M}$ Puffern muß der Niveauunterschied zwischen dem Stärkebreiblock und den Puffergefäßen mindestens 12 bis $15 \mathrm{~cm}$ betragen, da sonst zuvicl Puffer teils durch Kapillarkräfte, teils durch noch nicht geklärte Effekte in den Block gelangt. Bei Verwendung eines $0,05 \mathrm{M}$ Puffers muß der Niveauunterschied $22-25 \mathrm{~cm}$ betragen. Auf diese Weise erreicht man, daß der Block verhältnismäßig trocken und der Stromdurchgang niedrig bleibt. Man kann daher mit höheren Spannungen arbeiten. Das Anlegen hoher Spannungen und der verdünnte Puffer bewirken eine sehr rasche Auftrennung des Materials. Das war besonders im vorliegenden Falle wichtig, da große Mengen besonders kurzkettiger Fettsäureester bei einer zu langen Laufzeit hydrolysieren. Als Erfahrung von etwa 30 unter den oben geschilderten Bedingungen und bei verschiedenen $\mathrm{pH}$-Werten durchgeführten Elektrophoresen kann gesagt werden, daß eine Hydrolyse von Fettsäureestern um so rascher erfolgt, je kürzer die Kettenlänge der Säure und je höher der pH-Wert ist. Für einen statistischen Beleg liegt noch nicht genügend Material vor. Es wurden $25 \mathrm{~m} /$ biologisches Material aufgetragen, die Trennung erfolgte während 19 Stdn. bei $3800 \mathrm{~V}$ und $80-110 \mathrm{~mA}$, die Temperatur wurde bei $+1^{\circ} \mathrm{C}$ konstant gehalten.

Zur Aufarbeitung wurden die Stärkebreiblöcke so zerschnitten, $\mathrm{daB}$ je cm Blocklänge 2 Fraktionen erhalten wurden (Übergießen der abgeschnittenen Stärkescheibe mit $50 \mathrm{ml} 0,05 \mathrm{M}$ Tris-Essigsäure-Puffer $\mathrm{pH} 6,2$, unter häufigem Schütteln 24 Stdn. bei $2^{\circ}$ stehenlassen und anschließend Filtrieren durch ein hartes Faltenfilter, Fraktionsvolumen $35-40 \mathrm{~m} l$ ).

Die photometrische Bestimmung der gesamten veresterten Fettsäuren in den einzelnen Fraktionen erfolgte durch Extraktion eines aliquoten Anteils mit einem Gemisch aus Âther + Alkohol $=1+4$. Nach dem Entfernen des. Proteinniederschlages (Zentrifugieren) wurden in der überstehenden Lösung die gesamten veresterten Fettsäuren nach 1. c. (9) als Eisen-(1)-Hydrozamate photometrisch bestimmt. Unter Zugrundelegung eines mittlexen Molekulargewichtes von 277 erhält man gut reproduzierbare Werte. Nach dieser Methode wurde auch das zur Erzeugung der experimentellen Lipämie verwendete Lipofundin auf seinen Gehalt an gesamten veresterten Fettsäuren analysiert (Resultat: $9,962 \mathrm{~g} / 100 \mathrm{~m} l$, Angabe des Herstellers: $10,0 \mathrm{~g} / 100 \mathrm{ml}$ ). In den Elektrophoresediagrammen wurde aus Gründen der Einfachheit nur die jeweilige Extinktion ( $515 \mathrm{~nm}, 50 \mathrm{~mm}$ Schichtdicke) aufgetragen.

Zur Chromatographie wurde ein aliquoter Anteil jeder Fraktion gefriergetrocknet, gegen 0,01M Acetatpuffer $\mathrm{pH} 4,6$ dialysiert und erneut gefriergetrocknet. Der trockene Proteinrückstand wurde mit Äther-Alkohol (siehe oben) extrahiert, dex Extrakt im Stickstoffstrom und Hochvakuum zur Trockene gebracht und der Rückstand entsprechend der Vorschrift (9) in Eisen-(III)-Hydroxamate überführt (Endvolumen $0,5 \mathrm{~m} /$ ). Jede Fraktion, die veresterte Fettsäuren enthielt, wurde wie bei 1. c. (4) beschrieben auf mit $\mathrm{FeCl}_{3}$ in $\AA$ ther getränktem Papier absteigend chromatographiert; es wurden jeweils $0,3 \mathrm{~m} l$ strichförmig aufgetragen. Man erhält eine gute Auftrennung der Fettsäuren $C_{2}$ bis $C_{8}$. Längerkettige Fettsäuren haben denselben $R_{F}$-Wert wie Capryl- säure $\left(=C_{1}\right)$. Die Auswertung erfolgte nach dem Transparentmachen des Papieres im Schreiber (Elphor, Zeiss) und anschlieBendem Planimetrieren. Abbildung 2 zeigt als Beispiel ein Testchromatogramm. Die Fehlergrenze der Methode beträgt $\pm 6,8 \%$ (abs.).

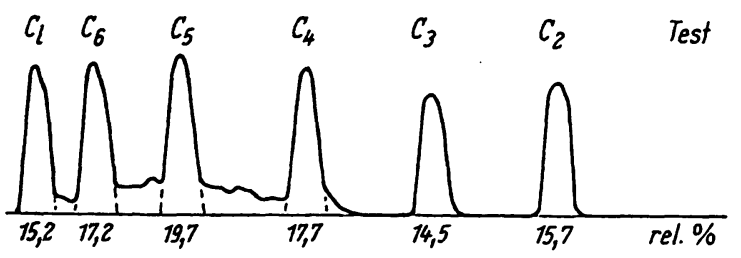

Abb. 2

Testchromatogramm der Fettsäuren $C_{2}$ bis $C_{1}$. Einzelheiten s. Text. Angaben in rel. \%.

Der Proteingebalt wurde durch Messung der Extinktion bei $279 \mathrm{~nm}$ und $5 \mathrm{~mm}$ Schichtdicke ermittclt.

Die Arylesterase wurde nach dem methodischen Prinzip (10) (mit Vergleichs- und Meßwerten) mit Phenylacetat als Substrat bestimmt (photometrische Bestimmung des nichtumgesetzten Substrates als Eisen-(III)-Hydroxamate in wäßriger Lösung nach 1.c. (11)). Die Bestimmung des Clearing Enzyms (endogene Lipoproteidlipase) wurde sowohl nach (12) (Trübungsmessung des entstandenen Calciumstearates) als auch nach der Methode (13) (photometrische Messung der Abnahme von veresterter Stearinsäure als Eisen-(III)-Hydroxamat) mit Tween 60 als Substrat durchgeführt. Mit beiden Methoden wurden identische Werte erhalten.

Cholesterin wurde nach der Methode von ZlatKis und Mitarbeitern (14) (modifiziert nach (16)) bestimmt.

\section{Ergebnisse}

Analyse des Ausgangsmaterials ( $a, b, c)$. Die Analyse der Seren (Ausgangsmaterial) ergab das in Tabelle 1 wiedergegebene Bild.

Tab. 1

Analyse des Ausgangsmaterials

\begin{tabular}{ccccc}
\hline Material & $\begin{array}{c}\text { gesamte } \\
\text { veresterte } \\
\text { Fettsäuren } \\
\text { mg/100 } \mathrm{ml}\end{array}$ & Cholesterin & $\begin{array}{c}\text { Clearing } \\
\text { Enzyme }\end{array}$ & Arylesterase* \\
\hline (a) & 295 & 54,7 & 32,6 & 1,07 \\
(b) & 921 & 65,2 & 23,4 & 0,60 \\
(c) & 332 & 55,6 & 30,0 & 0,97 \\
\hline
\end{tabular}

* Substrat: Phenylacetat.

Proteintrennung: Wegen der Gefahr der Verseifung von veresterten niederkettigen Fettsäuren während der Elektrophorese wurden umfangreiche Vorversuche auf Celluloseacetatfolie durchgeführt. Dabei wurde der niedrigste noch vertretbare $\mathrm{pH}$-Wert ermittelt. Abbildung 3 zeigt ein Elektrophoresediagramm (Celluloseacetatfolie, Färbung mit Ponceau S) bei pH 6,2 (Material a und b). Die Auftrennung ist gerade noch vertretbar.

Bei pH 5,9 treten bereits Verzerrungen der Banden bis zur Unkenntlichkeit auf.

Die präparative Auftrennung des Materials (a) ergibt das in Abbildung 4 wiedergegebene Bild. Wie ersichtlich, enthält Kaninchenserum mindestens 5 Peaks für veresterte Fettsäuren. Ein nur in quantitativer Hinsicht verändertes Bild wird bei der Auftrennung des 

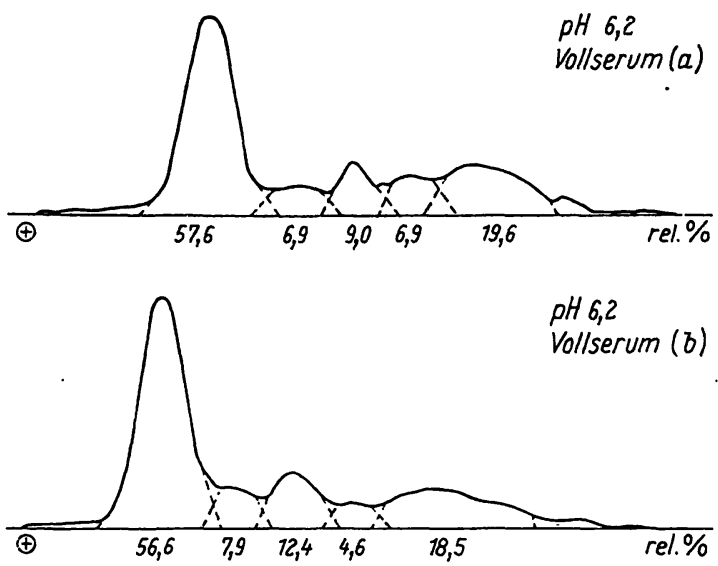

Abb. 3

Elektrophorese von'Material (a) und.(b) bei pH 6,2,0,05M TrisFissigsäure-Puffer. Celluloseacetatfolie, Färbung mit Ponceau S Angaben in rel. \%.

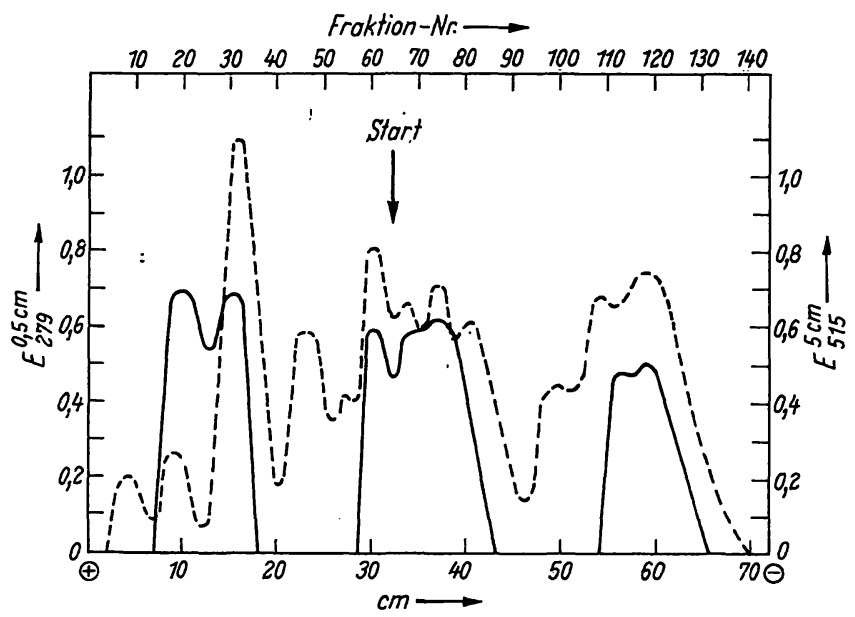

Abb. 4

Stärkebreielektrophorese (Ausschnitt) von Material (a). Einzelheiten s. Text.

Untere Abszisse: ausgewertete Blocklänge, obere Abszisse: Nummer der Fraktion. Linke Ordinate:

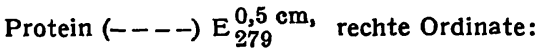

gesamte veresterte Fettsãuren $(\longrightarrow) E_{515}^{5} \mathbf{~ c m}$

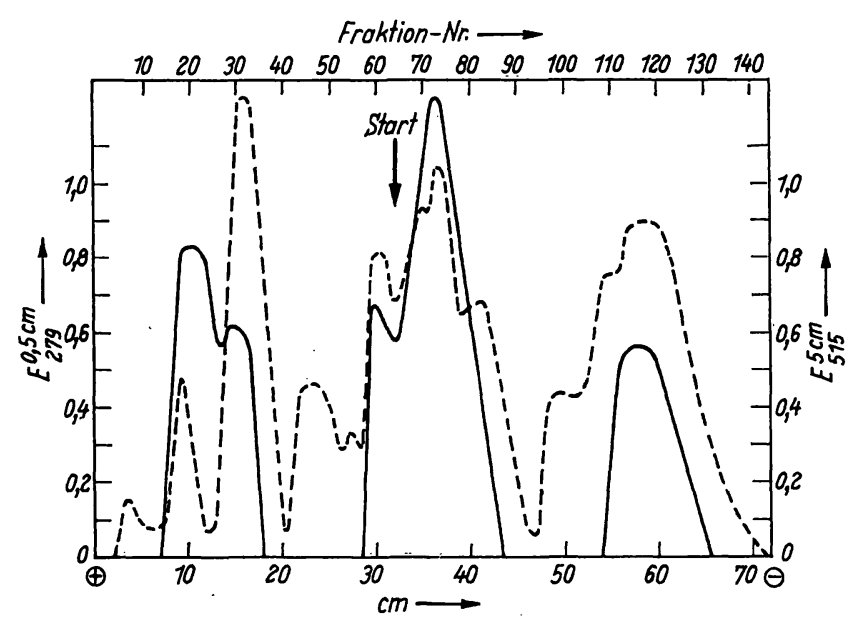

Abb. 5

Stärkebreielektrophorese (Ausschnitt) von Material (b). Legende s. Abb. 3 .
Materials (b) erhalten (Abb. 5). Eine gesonderte Wiedergabe des Stärkebreielektrophoresediagrammes von Material (c) erscheint unnötig, da das Bild mit Abbildung 4 (Material a) fast identisch ist.

Das Umesterungsverbalten von Proteinfraktionen, die veresterte kurzkettige Fettsäuren enthalten, wurde mit jenen Fraktionen genau untersucht, die den höchsten Anteil an veresterter Essigsäure hatten. Der Reaktionsansatz enthielt $10 \mathrm{mg}$ Proteinfraktion (Trockengewicht nach Gefriertrocknung und Dialyse), Natriumstearat in einer Konzentration, die den an den entsprechenden Proteinfraktionen veresterten kurzkettigen Fettsäuren entsprach (Mol-Verhältnis 1:1) (2), $\mathrm{pH} \quad 8,2,0,1 \mathrm{ml}$ Kaninchenserum (als Enzymquelle), Bebrütungszeit $5 \mathrm{Min}$. bei einem Endvolumen von $10 \mathrm{ml}$. Vor Zugabe des Kaninchenserums (Nüchternserum) wurden die Reaktionsansätze im Wasserbad auf $37^{\circ}$ gebracht, nach Beendigung der Bebrütungszeit die Reaktion durch Zusatz von Äther-Alkohol unterbrochen und die Menge der noch veresterten kurzkettigen Fettsäuren durch Überführung in Eisen-(III)-Hydroxamate, absteigende Papierchromatographie und quantitative Auswertung im Schreiber (wie oben beschrieben), bestimmt. In Abbildung 6 ist das Resultat wiedergegeben. Wie ersichtlich, verläuft die Umesterung bei den synthetischen Substraten wesentlich langsamer als bei den Tyrosin enthaltenden intakten Proteinfraktionen. Der Tyrosingehalt der untersuchten Fraktionen schwankte zwischen $4 \%$ und $6,6 \%$. Ähnlich wie beim Menschen sind bei Nüchternserum zwischen $80 \%$ und $90 \%$ der Tyrosin-OH-Gruppen mit Fettsäuren verestert.

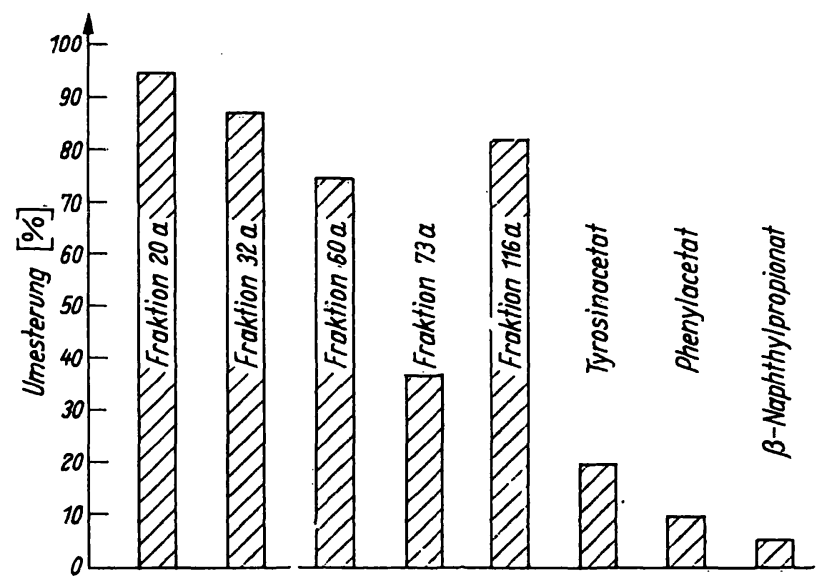

Abb. 6

Quantitativer Vergleich der Umesterung durch Arylesterase für verschiedene physiologische und synthetische Substrate. Abszisse: Substrat. Ordinate: Abnahme der veresterten kurzkettigen Fettsäuren $=$ Zunahme von langkettigen veresterten Fettsäuren (hier Stearinsäure). Reaktionszeit 5 Min. Einzelheițen s. Text.

Die Zusammensetzung der niederkettigen Fettsäuren während einer alimentären Lipämie in allen elektrophoretisch isolierten Fraktionen, die veresterte Fettsäuren enthielten, ist in den Tabellen 2 bis 5 wiedergegeben. Als Beispiele für die Analysenmethode sind die mit dem 
Tab. 2

Verteilung der veresterten Fettsäuren im Bereich des Präalbumins und Albumins vor, während und nach einer experimentellen Lipämie. Angaden in rel. $\% ;-=\left\langle 1 ; C_{1}=\right.$ Fettsäuren mit einer Kettenlänge von 8 und mehr C-Atomen

\begin{tabular}{|c|c|c|c|c|c|c|c|c|c|c|c|c|}
\hline \multirow{2}{*}{$\begin{array}{c}\text { Frakt. } \\
\text { Nr. }\end{array}$} & \multicolumn{4}{|c|}{ nüchtern (a) } & \multicolumn{4}{|c|}{ lipämisch (b) } & \multicolumn{4}{|c|}{24 Stdn. nach Lipämie (c) } \\
\hline & $C_{2}$ & $\mathrm{C}_{\mathbf{3}}$ & $\mathbf{C}_{\mathbf{6}}$ & $c_{1}$ & $C_{2}$ & $\mathbf{C}_{\mathbf{g}}$ & $\mathbf{C}_{\mathbf{B}}$ & $\mathrm{C}_{1}$ & $\mathrm{C}_{2}$ & $\mathrm{C}_{\mathbf{3}}$ & $\mathrm{C}_{5}$ & $\mathrm{C}_{1}$ \\
\hline $\begin{array}{l}18 \\
19 \\
20 \\
21 \\
22 \\
23 \\
24 \\
25 \\
26 \\
27 \\
28 \\
29 \\
30 \\
31 \\
32 \\
33 \\
34 \\
35\end{array}$ & $\begin{array}{r}61,2 \\
62,4 \\
63,3 \\
51,7 \\
47,6 \\
53,2 \\
44,4 \\
36,5 \\
23,8 \\
21,4 \\
19,8 \\
19,2 \\
17,5 \\
28,7 \\
42,4 \\
10,7 \\
4,2 \\
5,3\end{array}$ & $\begin{array}{l}= \\
= \\
= \\
= \\
= \\
= \\
= \\
=\end{array}$ & $\begin{array}{r}19,1 \\
18,6 \\
25,3 \\
21,3 \\
12,2 \\
6,7 \\
2,3 \\
1,2 \\
= \\
= \\
= \\
16,9 \\
3,2 \\
=\end{array}$ & $\begin{array}{r}19,7 \\
19,0 \\
11,4 \\
27,0 \\
40,2 \\
40,1 \\
53,3 \\
62,3 \\
76,2 \\
78,6 \\
80,2 \\
80,8 \\
82,5 \\
62,4 \\
41,3 \\
86,1 \\
95,8 \\
94,7\end{array}$ & $\begin{array}{r}23,0 \\
22,6 \\
15,4 \\
14,9 \\
14,3 \\
9,5 \\
4,7 \\
1,8 \\
1,1 \\
= \\
= \\
= \\
= \\
=\end{array}$ & $\begin{array}{l}= \\
= \\
= \\
= \\
= \\
= \\
= \\
= \\
=\end{array}$ & $\begin{array}{l}= \\
= \\
= \\
= \\
= \\
= \\
= \\
=\end{array}$ & $\begin{array}{c}77,0 \\
77,4 \\
84,6 \\
85,1 \\
85,7 \\
90,5 \\
95,3 \\
98,2 \\
98,9 \\
100 \\
100 \\
100 \\
100 \\
100 \\
100 \\
100 \\
100 \\
100\end{array}$ & $\begin{array}{r}60,6 \\
63,3 \\
64,2 \\
63,8 \\
41,1 \\
45,6 \\
39,6 \\
32,1 \\
18,7 \\
16,4 \\
16,1 \\
22,1 \\
33,6 \\
36,4 \\
40,0 \\
21,7 \\
7,3 \\
1,8\end{array}$ & $\begin{array}{l}= \\
= \\
= \\
= \\
= \\
= \\
= \\
=\end{array}$ & $\begin{array}{r}18,2 \\
17,8 \\
16,2 \\
12,3 \\
7,7 \\
2,1 \\
1,8 \\
= \\
= \\
\overline{1} \\
9,2 \\
12,3 \\
15,6 \\
3,4 \\
1,2 \\
-\end{array}$ & $\begin{array}{l}21,2 \\
18,9 \\
19,6 \\
23,9 \\
50,2 \\
52,3 \\
58,6 \\
67,9 \\
81,3 \\
83,6 \\
83,9 \\
76,7 \\
57,2 \\
51,3 \\
44,4 \\
74,9 \\
91,5 \\
98,2\end{array}$ \\
\hline
\end{tabular}

Tab. 3

Verteilung der veresterten Fettsäuren im Bereich der $\alpha$-Globuline vor, während und nach einer experimentellen Lipämie. Angaben in rel. \%; $-=<1 ; C_{1}=$ Fettsäuren mit einer Kettenlänge von 8 und mehr $C$-Atomen

\begin{tabular}{|c|c|c|c|c|c|c|c|c|c|c|c|c|}
\hline \multirow{2}{*}{$\begin{array}{c}\text { Frakt. } \\
\text { Nr. }\end{array}$} & \multicolumn{4}{|c|}{ nüchtern (a) } & \multicolumn{4}{|c|}{ lipämisch (b) } & \multicolumn{3}{|c|}{ (24 Stdn. nach Lipämie (c) } & \multirow[b]{2}{*}{$C_{1}$} \\
\hline & $\mathrm{C}_{2}$ & $\mathrm{C}_{3}$ & $\mathrm{C}_{8}$ & $\mathrm{C}_{1}$ & $C_{2}$ & $\mathrm{C}_{3}$ & $\mathrm{C}_{8}$ & $\mathrm{C}_{\mathrm{l}}$ & $\mathrm{C}_{2}$ & $\mathrm{C}_{\mathbf{3}}$ & $\mathrm{C}_{6}$ & \\
\hline $\begin{array}{l}58 \\
59 \\
60 \\
61 \\
62 \\
63 \\
64\end{array}$ & $\begin{array}{r}19,8 \\
21,4 \\
22,0 \\
20,6 \\
14,5 \\
9,2 \\
6,3\end{array}$ & $\begin{array}{l}= \\
= \\
=\end{array}$ & $\begin{array}{l}= \\
= \\
\bar{z}\end{array}$ & $\begin{array}{l}80,2 \\
78,6 \\
78,0 \\
79,4 \\
85,5 \\
90,8 \\
93,7\end{array}$ & $\begin{array}{r}2,9 \\
7,2 \\
10,6 \\
6,1 \\
2,8 \\
1,7 \\
1,9\end{array}$ & $\begin{array}{l}= \\
= \\
=\end{array}$ & $\begin{array}{l}= \\
= \\
=\end{array}$ & $\begin{array}{l}97,1 \\
92,8 \\
89,4 \\
93,9 \\
97,2 \\
98,3 \\
98,1\end{array}$ & $\begin{array}{r}16,2 \\
18,3 \\
20,3 \\
18,8 \\
13,7 \\
5,3 \\
2,7\end{array}$ & $\begin{array}{l}= \\
= \\
=\end{array}$ & $\begin{array}{l}= \\
\bar{E} \\
=\end{array}$ & $\begin{array}{l}83,8 \\
81,7 \\
79,7 \\
81,2 \\
86,3 \\
94,7 \\
97,3\end{array}$ \\
\hline
\end{tabular}

Tab. 4

Verteilung der veresterten Fettsäuren im B'ereich der $\beta$-Globuline vor, während und nach einer experimentellen Lipämie. Angaben in rel. \%;

\begin{tabular}{|c|c|c|c|c|c|c|c|c|c|c|c|c|}
\hline \multirow{2}{*}{$\begin{array}{l}\text { Frakt. } \\
\text { Nr. }\end{array}$} & \multicolumn{4}{|c|}{ nüchtern (a) } & \multicolumn{4}{|c|}{ lipämisch (b) } & \multicolumn{4}{|c|}{24 Stdn. nach Lipämie (c) } \\
\hline & $\mathrm{C}_{2}$ & $\mathrm{C}_{\mathbf{s}}$ & $\mathrm{C}_{8}$ & $\mathrm{c}_{1}$ & $C_{2}$ & $\mathrm{C}_{3}$ & $\mathrm{C}_{8}$ & $\mathrm{C}_{1}$ & $\mathrm{C}_{2}$ & $\mathrm{C}_{3}$ & $\mathrm{C}_{8}$ & $C_{1}$ \\
\hline $\begin{array}{l}65 \\
66 \\
67 \\
68 \\
69 \\
70 \\
71 \\
72 \\
73 \\
74 \\
75 \\
76 \\
77 \\
78 \\
79 \\
80 \\
81 \\
82\end{array}$ & $\begin{array}{r}4,6 \\
3,7 \\
5,2 \\
4,8 \\
5,8 \\
5,1 \\
5,9 \\
9,8 \\
14,0 \\
10,2 \\
6,1 \\
5,3 \\
5,7 \\
4,8 \\
4,3 \\
2,8 \\
3,7 \\
3,1\end{array}$ & $\begin{array}{l}= \\
= \\
= \\
= \\
= \\
= \\
= \\
= \\
=\end{array}$ & $\begin{array}{l}= \\
= \\
= \\
= \\
= \\
= \\
= \\
= \\
=\end{array}$ & $\begin{array}{l}95,4 \\
96,3 \\
94,8 \\
95,2 \\
94,2 \\
94,9 \\
94,1 \\
90,2 \\
86,0 \\
89,8 \\
93,9 \\
94,7 \\
94,3 \\
95,2 \\
95,7 \\
97,2 \\
96,3 \\
96,9\end{array}$ & $\begin{array}{l}= \\
= \\
= \\
= \\
= \\
= \\
= \\
=\end{array}$ & $\begin{array}{l}= \\
= \\
= \\
= \\
= \\
= \\
= \\
=\end{array}$ & $\begin{array}{l}= \\
= \\
= \\
= \\
= \\
= \\
= \\
= \\
=\end{array}$ & $\begin{array}{l}100 \\
100 \\
100 \\
100 \\
100 \\
100 \\
100 \\
100 \\
100 \\
100 \\
100 \\
100 \\
100 \\
100 \\
100 \\
100 \\
100 \\
100\end{array}$ & $\begin{array}{l}2,8 \\
.3,9 \\
1,6 \\
2,5 \\
3,8 \\
4,3 \\
5,6 \\
7,7 \\
9,4 \\
9,1 \\
5,2 \\
3,7 \\
2,4 \\
3,1 \\
1,9 \\
2,0 \\
1,2 \\
1,2\end{array}$ & $\begin{array}{l}= \\
= \\
= \\
= \\
= \\
= \\
= \\
=\end{array}$ & $\begin{array}{l}= \\
= \\
= \\
= \\
= \\
= \\
= \\
= \\
=\end{array}$ & $\begin{array}{l}97,2 \\
96,1 \\
98,4 \\
97,5 \\
96,2 \\
95,7 \\
94,4 \\
92,3 \\
90,6 \\
90,9 \\
94,8 \\
96,3 \\
97,6 \\
96,9 \\
98,1 \\
98,0 \\
98,0 \\
98,8\end{array}$ \\
\hline
\end{tabular}

Tab. 5

Yerteilung der veresterten Fettsäuren im Bereịch der $\gamma$-Globuline vor, während und nach einer experimentellen Lipämie. Angaben in rel. \%; Yerteilung der veresterten Fettsâuren im $=\left\langle 1 ; \mathrm{C}_{1}=\right.$ Fetsäuren mit einer Kettenlänge von 8 und mehr C-Atomen

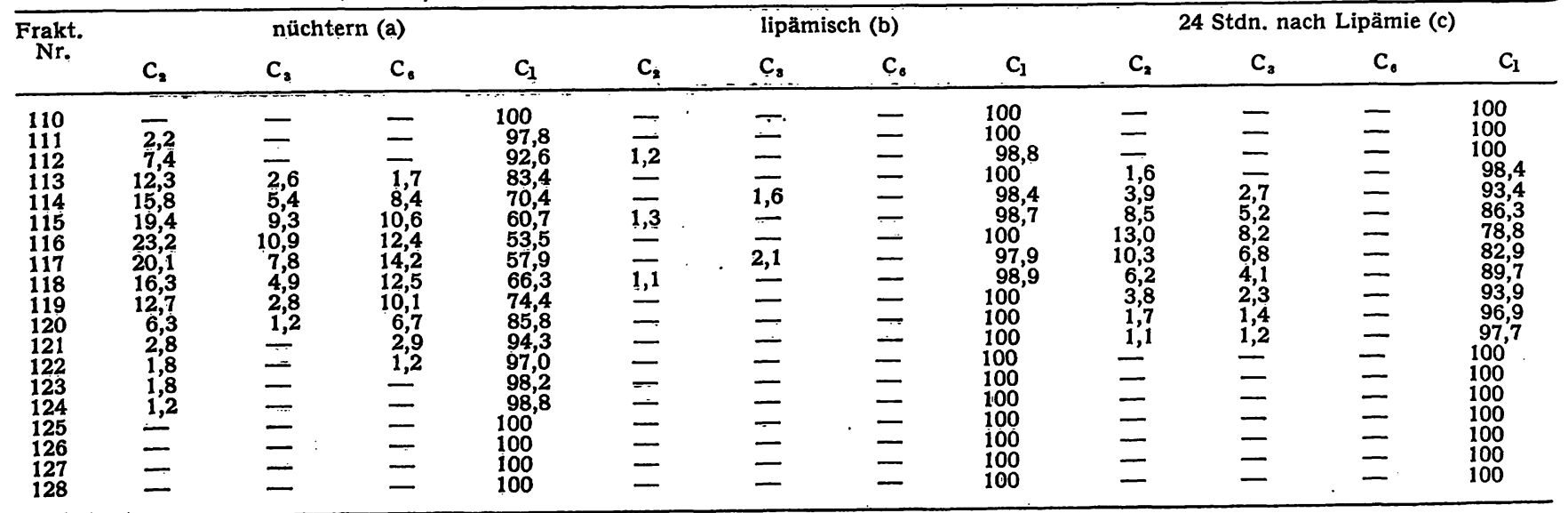


Schreiber erhaltenen Kurven für die Fraktionen 60 (Abb. 7) und 116 (Abb. 8) dargestellt. Wir wählten diese Beispiele aus, weil diese die Fraktionen mit den jeweils höchsten Anteilen an veresterter Essigsäure waren.
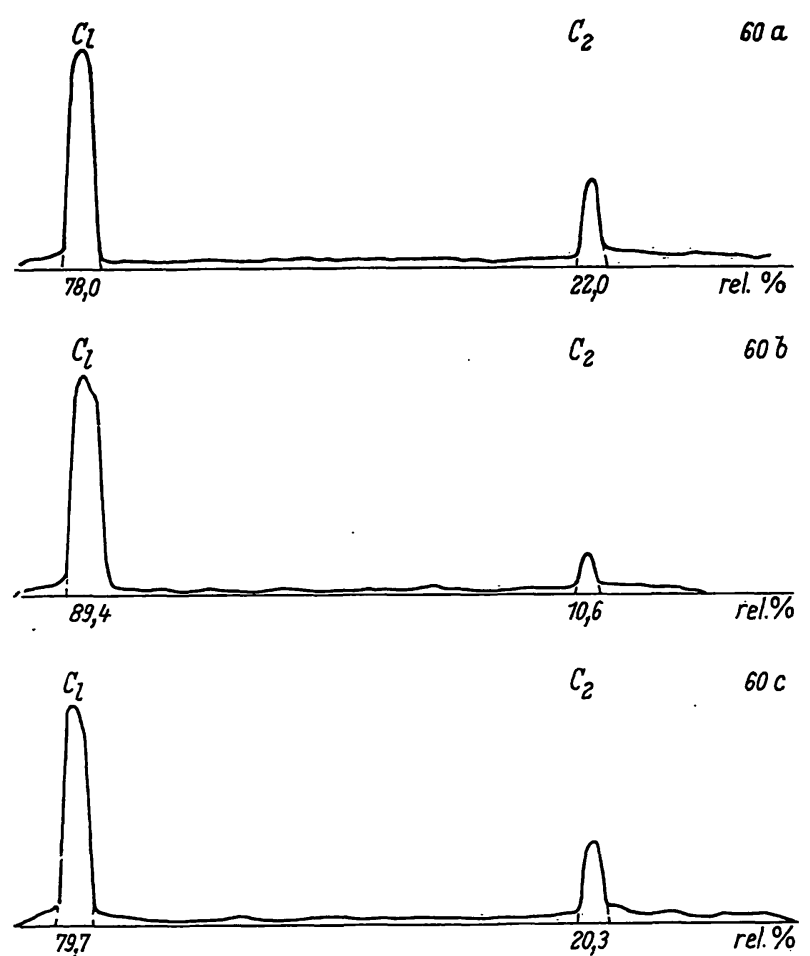

Abb. 7

Fettsäureverteilung der Fraktion 60 (Material a, b und c). Angaben in rel. \%.
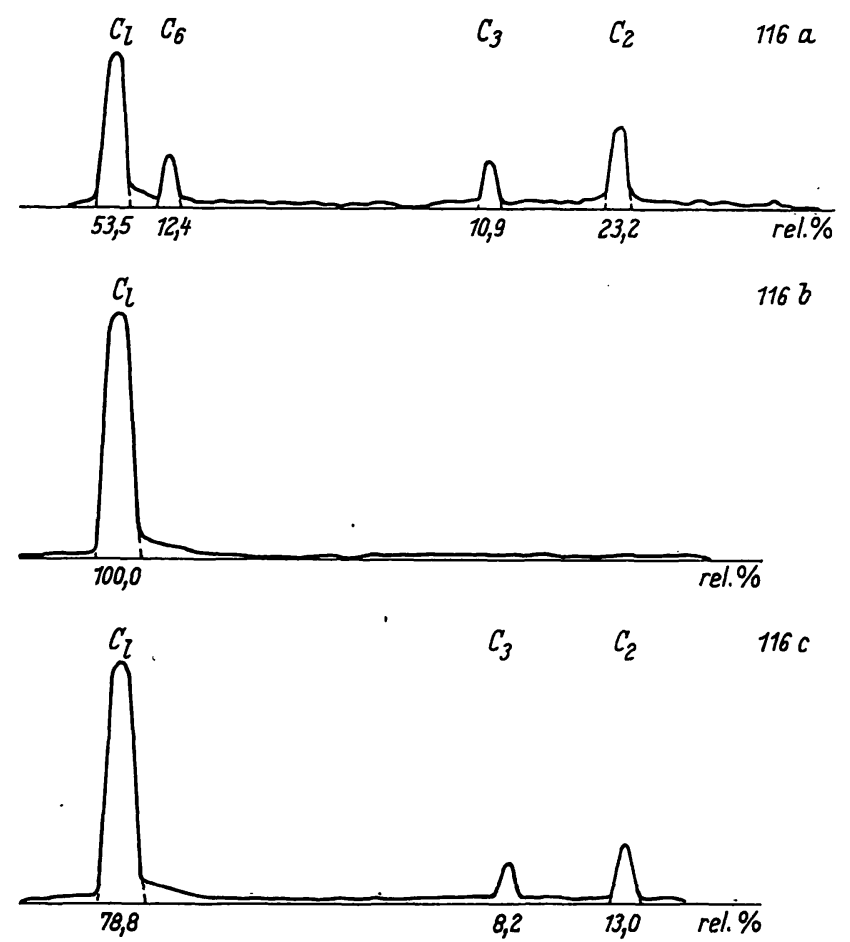

Abb. 8

Fettsäureverteilung der Fraktion 116 (Material a, b und c). Angaben in rel. \%.

\section{Diskussion}

Bei der Analyse des Ausgangsmaterials fällt auf, daß die Konzentration an gesamten veresterten Fettsäuren und Cholesterin im Nüchternserum wesentlich geringer ist als beim Menschen. Dagegen sind die Werte für die endogene Lipoproteidlipase (Clearing Enzym) wesentlich höher. Die Werte für die Arylesterase können nicht mit den Werten im menschlichen Serum verglichen werden, da die Arylesterasen des Kaninchenserums ein anderes Substratoptimum (andere Kettenlängen der veresterten Fettsäuren) haben.

Gemessen an einer Laufzeit von $19 \mathrm{Stdn}$. und einem $\mathrm{pH}-$ Wert von $\mathrm{pH}$ 6,2 kann die Proteinauftrennung in der präparativen Stärkebreielektrophorese als gut bezeichnet werden. Eine weitere Auftrennung ist ohne weiteres möglich (vgl. l. c. (6)), jedoch ändert sich dabei das Fettsäurespektrum der einzelnen Fraktionen durch Abspaltung von niederkettigen Fettsäuren nicht unerheblich. $\mathrm{DaB}$ am Start liegengebliebenes Protein vorhanden ist, ist eine Folge der kurzen Laufzeit und muß in Kauf genommen werden.

Abbildung 6 beweist, da $\beta$ Proteinfraktionen, die niederkettige veresterte Fettsäuren enthalten, in Gegenwart von Arylesterase und langkettigen freien Fettsäuren die niederkettigen Fettsäuren mit hoher $\mathrm{Ge}$ schwindigkeit gegen langkettige Fettsäuren austauschen. Diese Umesterungsteaktion läuft mit Proteinfraktionen wesentlich rascher ab als mit synthetischen Substraten wie Tyrosinacetat, Phenylacetat oder $\beta$-Naphthylpropionat. Offensichtlich sind solche Fraktionen die physiologischen Substrate für die an synthetischen Substraten gefundene Umesterung $(2,4,5)$.

Als weiterer Beweis kann die Konzentrationsänderung der niederkettigen Fettsäuren im Nüchternzustand und im Zustand der Lipämie herangezogen werden. Fast alle Lipoide enthaltenden Fraktionen des.Serums (a) enthalten auch erhebliche Anteile an veresterter Essigsäure, am meisten die Fraktionen im Präalbumin und Albumin (vgl. Tab. 2). Desgleichen sind auch die Fettsäuren der Kettenlänge $C_{3}, C_{5}$ und $C_{6}$, wenn auch in wesentlich geringeren Mengen, in veresterter Form vorhanden. Veresterte Propionsäure und veresterte Capronsäure finden sich in den $\gamma$-Fraktionen des Serums (vg]. Tab. 5). Dagegen sind die Anteile der Acetylreste in den $\alpha=$ und $\beta$-Fraktionen verhältnismäßig gering, niederkettige Fettsäuren anderer Kettenlängen kommen in diesen Bereichen nicht vor (Tab. 3 und 4).

Im Zustand einer alimentären Lipämie nimmt die Menge der veresterten niederkettigen Fettsäuren stark zugunsten von langkettigen Fettsäuren ab. Trotzdem sind im Bereich des Präalbumins und des $\alpha$-Globulins immer noch kleine Mengen von verestertèn Acetylgruppen vorhanden, während alle anderen kurzkettigen Fettsäuren bis auf ganz kleine Anteile ver-. schwunden sind.

Das ist damit erklärbar, daß aus der Leber (wo eine Umesterung im entgegengesetzten Sinn stattfindet 
$(5,6))$ laufend neue niederkettige Fettsäuren als Ester in das Serum abgegeben werden. Demnach hat man es im Serum stets mit einem Gleichgewicht zwischen veresterten kurzkettigen und veresterten langkettigen Fettsäuren zu tun. Die rasche Einstellung des Gleichgewichtes wird von den Arylesterasen katalysiert, die jeweilige Gleichgewichtslage hängt von der Menge der von der Lipoproteidlipase hydrolysierten Lipoproteide mit langkettigen Fettsäuren, also letztlich vom Angebot an freien langkettigen Fettsäuren ab. Da auch die Lipoproteidlipase nur die rasche Einstellung eines Gleichgewichtes bewirken kann, das Enzym aber spezifisch durch langkettige freie Fettsäuren gehemmt wird (12), ist ein funktionsfähiges Arylesterasesystem unbedingt notwendig, um die physiologische Hydrolyse von Lipoproteiden zu gewährleisten.

Nach dem Abklingen der Lipämie (c) ist zwar der Zustand, wie er im Nüchternserum (a) gefunden wurde, noch nicht wieder erreicht, jedoch ist der Unterschied in der Fettsäureverteilung zwischen den Seren (a) und (c) nur mehr gering. Das kann in Richtung einer Rückentwicklung zum Ausgangszustand (a) gewertet werden.

Wir geben diese Befunde bekannt, um deutlich zu machen, daß auch das Arylesterasesystem des Kaninchens, dessen Darstellung gesondert erfolgt, ein Fermentsystem des Fettstoffwechsels; speziell des Transportes von unveresterten Fettsäuren im Sinne von 1. c. $(2,4,5)$ ist. Die vorgelegten Befunde mögen besonders deshalb von Interesse sein, weil Kaninchen normalerweise nicht lipämisch werden und es uns nicht gelang, durch spezielle Fütterung eine alimentäre Lipämie bei Kaninchen zu erzeugen. Eine alimentäre Lipämie ist beim Kaninchen offenbar etwas sehr seltenes, um so deutlicher lassen sich die Transportmechanismen für die freien Fettsäuren verfolgen.

Analoge Untersuchungen beim Menschen sind nur schwer durchzuführen, da die Beschaffung ausreichender Mengen biologischen Materials schwierig ist. Beweisend wäre nach unserer Ansicht nur die Verfolgung einer alimentären Lipämie an einem Menschen. Bisher konnten wir dafür noch keinen Probanden finden.

Isolierte Untersuchungen mit Serum nüchterner Versuchspersonen erbrachten ähnliche Ergebnisse wie beim Kaninchen, jedoch fehlt beim Menschen die lipidische $\gamma$-Fraktion. Als veresterte kurzkettige Fettsäuren kommen sowohl Essig- und Propionsäure (Hauptmenge) als auch Fettsäuren der Kettenlänge $C_{4}$ bis $C_{6}$ (in sehr kleinen Mengen) vor; auch Spuren von veresterter Ameisensäure sind nachweisbar. Lipämisches Serum enthält nur Spuren kurzkettiger Fettsäuren. Im Vergleich zum Kaninchen ist beim Menschen das lipidische Präalbumin wesentlich stärker ausgeprägt. Das würde die Arbeiten von LošrIckŸ und Mitarbeitern (15) bestätigen. Sobald wir ausreichendes Material auch an Untersuchungsgut vom Menschen haben, werden wir es bekanntgeben.

Wir danken der Firma Camag, Muttenz, für die reichlich gewährte Unterstützung auf apparativem Gebiet.

\section{Literatur}

1. Pisz, W., Hoppe-Seyler's Z. physiol. Chem., 328, 1 (1962). -

2. Pruz, W. und H. Hörurin, Hoppe-Seyler's Z. physiol. Chem., 335, 221 (1964). - 3. Przz, W., Mikrochim. Acta, 164 (1961). 4. PIrz, W., Hoppe-Seyler's Z. physiol. Chem., 338, 238 (1964). 5. Pruz, W., H. HörLenN und E. Stelza, Hoppe-Seyler's $Z$. physiol. Chem., 345, 65 (1966). - 6. Przz, W. und E. StelzL, in Vorbereitung. - 7. Pruz, W., Hoppe-Seyler's Z. physiol. Chem., 345, 80 (1966). - 8. Prutz, W. und I. JohanN, Z. analyt. Chem., 215, 105 (1966). - 9. Przz, W., Z. analyt. Chem., 193, 338 (1963).10. Pruz, W., Zschr. exper. Med., 132, 310 (1959). - 11. Przz, W.,
Z. analyt. Chem., 162, 81 (1958). - 12. HöRLEIN H. und W. PrLZ, Hoppe-Seyler's Z. physiol. Chem., 327, 256 (1962). - 13. Pizz, W. und I. JohanN, Z. analyt. Chem., 218, 426 (1966). - 14. ZlatKIs, A., B. JAK und A. J. Borne, J. Laborat. Clin. Med. (S. Louis) 41, 486 (1953). - 15. Loštrckł́, C., Clin. chim. Acta (Amstetdam) 8, 859 (1963). Lošrrckł und M. RYBák, Clin. chim. Acta (Amsterdam) 10, 559 (1964). Lošrickצ́, C., Hoppe-Seyler's Z. physiol. Chem., 342, 13 (1965). - 16. Pruz, W., Z. analyt. Chem., im Druck.

Dr. Wolfgang Pịlz,

Leiter des physiol.-chem. u. analyt. Labors derärztl. Abt. der æarbenfabriken Bayer A. G., 509 Leverkusen-Bayerwerk 